\title{
A Typology of Personal and Environmental Sexual Harassment: Research and Policy Implications for the $1990 \mathrm{~s}^{1}$
}

\author{
James E. Gruber \\ University of Michigan-Dearborn
}

Most of the research conducted on sexual harassment over the last decade and a half has used categories that are neither mutually exclusive nor exhaustive. This has created problems for researchers: it is difficult to compare results from one study to another, harassment types that have scholarly and legal-policy relevance are omitted, and the ability of researchers to inform legal and policy decisions is diminished as a result of these problems. A comprehensive categorization of harassment types that addresses these methodological problems is presented. Specifically, 11 specific types of harassment-4 types of Verbal Requests, 3 Verbal Remarks, and 4 Nonverbal Displays-are presented with examples from research and legal literatures. Recommendations for reconceptualizing research definitions of harassment as well as for diversifying the methodological approaches to the topic are made.

Previous research has shown that sexual harassment is a significant problem in educational and work environments. Despite the pervasiveness of the problem and the considerable number of studies that have been published over the last decade and a half, there is nevertheless substantial confusion over definitions of sexual harassment as well as operationalizations of these definitions into meaningful, empirical harassment categories. Some of the conceptual and methodological problems have been reviewed recently by Gillespie and Leffler (1987), McKinney (1990), and Gruber (1990). The purpose of this paper is to develop a comprehensive catego-

\footnotetext{
${ }^{1}$ The author is indebted to the Center for Research on Women at Wellesley College for their support and encouragement during his sabbatical in the fall of 1988.
} 
rization of sexual harassment that is mutually exclusive and exhaustive, and that is reflective of the recent guidelines of the Equal Employment Opportunity Commission (EEOC; 1988).

As I will describe later, most research has shortcomings in both areas. Our task is fueled by two concerns. First, until we have observational or enumerative categories that are sensitive to the range and complexity of sexual harassment experiences, researchers cannot accurately answer such straightforward questions as the following: How many women have experienced harassment? Do some women receive different types of harassment than others? Are some occupations or organizational environments more harassment prone? Second, as both a researcher and a legal consultant in the area of sexual harassment I share concerns with others in the field who find it difficult to provide the courts or policymakers with clear and concise information because of the gaps between research and legal conceptualizations of harassment.

Table I. Research Characteristics of Select Harassment Studies

\begin{tabular}{|c|c|c|}
\hline Surveys & Sample composition & $N$ of women \\
\hline \multicolumn{3}{|l|}{ Cross-sectional samples } \\
\hline $\begin{array}{l}\text { Canadian Human Rights } \\
\text { Commission (1983) }\end{array}$ & Canadian Workers & 1034 \\
\hline Gutek (1985) & Los Angeles County residents & 827 \\
\hline Loy and Stewart (1984) & Connecticul residents & 304 \\
\hline Webking (1979) & Lethridge, Alberta residents & 80 \\
\hline Schneider (1982) & $\begin{array}{l}\text { New England residents } \\
\text { (heterosexuals) }\end{array}$ & 386 \\
\hline \multicolumn{3}{|l|}{ Public sector samples } \\
\hline Hayler (1979) & State of Illinois employees & 1495 \\
\hline McIntyre (1982) & State of Florida employees & 956 \\
\hline Stringer-Moore (1982) & City of Seattle & 579 \\
\hline $\begin{array}{l}\text { U.S. Merit Systems } \\
\text { Protection Board (1981) }\end{array}$ & Nationwide federal employees & 10,648 \\
\hline \multicolumn{3}{|l|}{ Private sector samples } \\
\hline Gruber and Bjorn (1982) & Michigan autoworkers & 150 \\
\hline Maypole (1986) & Iowa Social Workers & 188 \\
\hline Maypole and Skaine (1982) & Iowa manufacturing workers & 160 \\
\hline Littler-Bishop et al. (1982) & Flight attendants & 81 \\
\hline Lafontaine and Tredeau (1986) & $\begin{array}{l}\text { Professionals in nontraditional } \\
\text { jobs }\end{array}$ & 160 \\
\hline \multicolumn{3}{|l|}{ University samples } \\
\hline Benson and Thomson (1982) & UC-Berkeley seniors & 269 \\
\hline Cammaert (1985) & University of Calgary students & 348 \\
\hline Verba et al. $(1983)^{a}$ & $\begin{array}{l}\text { Harvard University students } \\
\text { and faculty }\end{array}$ & 1141 \\
\hline
\end{tabular}

${ }^{a}$ Figures are for those harassed by "someone in authority." 
Table II. Sexual Harassment Types in 17 Studies

\begin{tabular}{|c|c|}
\hline Types & Sources $^{a}$ \\
\hline Pressure for sex favors & $\begin{array}{l}\text { Schneider (1982); Hayler; McIntyre; USMSPB; Lafontaine } \\
\text { and Tredeau ("overt demands for sexual activity"); Verba } \\
\text { et al. }\end{array}$ \\
\hline Sexual advances & Webking; Cammaert \\
\hline Sexual bribery & $\begin{array}{l}\text { Gutek ("expected sexual activity"); Loy and Stewart } \\
\text { ("verbal negotiations"); Gruber and Bjorn; Benson and } \\
\text { Thomson }\end{array}$ \\
\hline Expected social activity & Gutek \\
\hline Sexual propositions & Gruber and Bjorn \\
\hline Verbal advances & Benson and Thomson \\
\hline Subtle hints/pressures & $\begin{array}{l}\text { CHRC; Hayler; McIntyre; Gruber and Bjorn ("verbal } \\
\text { innuendo"); Lafontaine and Tredeau }\end{array}$ \\
\hline $\begin{array}{l}\text { Pressure for } \\
\text { relationship/dates }\end{array}$ & $\begin{array}{l}\text { CHRC; Schneider (1982); Hayler; McIntyre; USMSPB; } \\
\text { Stringer-Moore; Benson and Thomson ("invitations"); } \\
\text { Verba et al. }\end{array}$ \\
\hline $\begin{array}{l}\text { Letters/phone } \\
\text { calls/materials }\end{array}$ & USMSPB; Stringer-Moore; Verba et al. \\
\hline Teasing/questions/remarks & $\begin{array}{l}\text { CHRC; Loy and Stewart ("verbal commentary"); } \\
\text { Schneider (1982); Hayler; McIntyre; USMSPB; } \\
\text { Stringer-Moore; Verba et al. }\end{array}$ \\
\hline Sexual comments & $\begin{array}{l}\text { Gutek; Webking; Maypole; Maypole and Skaine; } \\
\text { Littler-Bishop et al.; Lafontaine and Tredeau; Cammaert }\end{array}$ \\
\hline Abusive language & Gruber and Bjorn; Benson and Thomson \\
\hline Emotional come-ons & Benson and Thomson \\
\hline Unclue attention & Benson and Thomson \\
\hline Social derogation & Gruber and Bjorn \\
\hline Nonverbal & Cammaert \\
\hline Looks/stares/gestures & $\begin{array}{l}\text { CHRC; Gutek; Hayler; McIntyre; USMSPB; } \\
\text { Stringer-Moore; Littler-Bishop et al.; Lafontaine and } \\
\text { Tredeau; Gruber and Bjorn, and Benson and Thomson } \\
\text { ("Body Language"); Verba et al. }\end{array}$ \\
\hline Touching/cornering & $\begin{array}{l}\text { CHRC; Gutek; Loy and Stewart ("manhandling"); } \\
\text { Webking; Schneider (1982); Hayler; McIntyre; USMSPB; } \\
\text { Stringer-Moore; Gruber and Bjorn ("physical attacks"); } \\
\text { Maypole; Maypole and Skaine; Littler-Bishop et al.; } \\
\text { Lafontaine and Tredeau ("touching/patting/pinching" and } \\
\text { "brushing against"); Benson and Thomson; Cammaert; } \\
\text { Verba et al. }\end{array}$ \\
\hline Sexual assault & $\begin{array}{l}\text { CHRC; Loy and Stewart; Hayler; McIntyre; USMSPB; } \\
\text { Stringer-Moore; Maypole and Skaine; Lafontaine and } \\
\text { Tredeau; Cammaert; Verba et al. }\end{array}$ \\
\hline
\end{tabular}

${ }^{a}$ Individual category variations from a specific type are noted in parentheses next to the source.

Recently, I began an analysis of the conceptual and methodological problems in sexual harassment research by evaluating the harassment categorizations or typologies of seventeen studies that were published over the last decade (see Table I). 
I discovered two major problems with these categorizations: similar harassment experiences were denoted by different labels, and the categories presented in most of these studies were not mutually exclusive and exhaustive. As an illustration of the first problem a category for quid pro quo sexual advances was called "sexual bribery" by some (Benson \& Thomson, 1982; Gruber \& Bjorn, 1982) and "verbal negotiations" by others. Similarly, "pressure for sex favors," which appears in 6 studies is termed "overt demand for sexual activity" by Lafontaine and Tredeau (1986). Also, some studies seem to have too few categories and subsume too much information under one category (e.g., Webking, 1979; Maypole \& Skaine, 1982) compared to others that have as many as 7 [e.g., Hayler, 1979; United States Merit Systems Protection Board (USMSPB), 1981]. Even more disconcerting is that many studies omitted legally relevant categories altogether. Only 4 of the 17 studies included "sexual bribery," the earliest and clearest legal standard of harassment, and none gave adequate coverage to "environmental" forms of harassment (Vhay, 1988), which were incorporated in sexual harassment law in the last half of the 1980s.

The 17 studies (see Table I) were included for review because they represent a broad spectrum of survey research studies on women's experiences with harassment that had been published at the time this project was undertaken (late 1980s). These studies were selected because they employed representative sampling techniques, dealt with women's actual experiences with harassment, and represent a wide variety of occupations and organizations in the U.S. and Canada. Experimental studies or other research that tapped respondents' perceptions or definitions of harassment were not included since they address a related but distinct area of research inquiry, namely harassment severity. Such studies typically used written or visual scenarios to determine how respondents distinguish between serious and trivial harassment. An analysis that uses the studies in this research vein to develop a research and legal standard for harassment severity is presented elsewhere.

Finally, data on the harassment experiences of men were excluded because a considerable body of research (e.g., USMSPB, 1981; Gutek, 1985) shows that men's and women's experiences with and perceptions of harassment differ significantly. Excluding data on men's experiences removes a potential source of confusion from the development of harassment categories from previous research, namely that differences in categorization among these studies is a function of gender differences. A total of 35 harassment categories were enumerated (see Table II). These were reduced to 19 substantive categories by comparing definitions and operationalizations, and subsequently combining terms that referred to the same harassment experience. An end point of that paper-the enumeration of 19 terms-is the point of departure for the present paper. 
Table III. A Typology of Sexual Harassment

\begin{tabular}{ll}
\hline Harassment types & Descriptions \\
\hline
\end{tabular}

A. Verbal requests (more to less severe)

1. Sexual bribery

2. Sexual advances

3. Relational advances

A request with a threat and/or promise of reward: a quid pro quo. Examples: offers of money for sex; offers of better working conditions for sex.

A request without a threat or promise that seeks sexual intimacy. May be in the form of questions or statements expressing a sexual interest. Examples: "Will you be my lover?" "How would you like this (beard) between your legs?" Statements indicating intentions or desires ("I'd like to ... or "When I see you I want to ...") of a sexual nature.

Request without a threat or promise that seeks a social relationship. Sexual desire or intent is not stated or implied. These are harassful by virtue of repetition (e.g., "nagging", "badgering"). Women often complain of men who "won't take no for an answer."

4. Subtle pressures/ advances

B. Verbal Comments (more to less severe)

1. Personal remarks Statements in which the goal or the target of the request is implicit or ambiguous. Their harassing nature is seen most clearly through an analysis of the full context of the interactions. Examples: double entendres; "Wishing out loud" comments ("I need some TLC"; "I'm really horny today"); or inappropriate personal questions ("Would you ever date a married man?" "Have you ever had an affair?").

Comments or questions of a nonsolicitory nature directed to a woman: includes jokes, teasing, questions about sexuality or appearance, and semantic derogation. Some solicitations are "remarks" because of the context. Examples: requests for body measurements; comments attributing a state of sexual arousal to the harassed; sexual slurs.

2. Subjective objectification

3. Sexual categorical remarks

C. Nonverbal displays (more to less severe)

1. Sexual assault Remarks about a woman either in her presence or in the form of rumors. The recipient is "invisible" or physically absent from the sexual discussion of her. Examples: rumors of alleged lesbianism or sexual promiscuity; public discussion about the harassed's body or sexuality. Sexually based comments about other women or women "in general." Includes comments which slur womanhood or particular groups or categories of women. Also bystander harassment, witnessing the requests or remarks of a harassing nature addressed to specific other women, is categorized here. Examples: "Women are whores"; women in a department are called the "cunt brigade"; a female co-worker's sexual anatomy is discussed in front of other women.

A prolonged or intense and aggressive form of sexual contact involving coercion. Examples: actual or attempted intercourse; fondling recipient's sexual anatomy. 
Table III. Continued

\begin{tabular}{|c|c|}
\hline Harassment types & Descriptions \\
\hline 2. Sexual touching & $\begin{array}{l}\text { Includes both sexual and sexualized touching. The former } \\
\text { is more brief and more spontaneous than sexual assault } \\
\text { (e.g., a pinch, a grab) so that the terms "coercion" and } \\
\text { "resistance" do not apply well. The latter requires greater } \\
\text { understanding of the context of the interaction than the } \\
\text { former. }\end{array}$ \\
\hline 3. Sexual posturing & $\begin{array}{l}\text { Includes violations of personal space and attempts to (or } \\
\text { threats to) have physical contact. Distinctions should be } \\
\text { made as to whether the posturing involves her directly } \\
\text { (e.g., following or cornering; attempted grabs), as an } \\
\text { audience member (e.g., men feigning masturbation with } \\
\text { each other), or as a bystander (recipient observes other } \\
\text { women being approached directly, touched, or assaulted). }\end{array}$ \\
\hline 4. Sexual materials & $\begin{array}{l}\text { Pornographic materials or objects which sexually debase } \\
\text { women or womanhood (movies, magazines, pictures, "sex } \\
\text { toys"). Also, the profanation of women's sexuality or } \\
\text { personal items (e.g., underwear, menstrual cycle). }\end{array}$ \\
\hline
\end{tabular}

\section{THE VARIETIES OF SEXUAL HARASSMENT}

How many distinctive types of sexual harassment are there? I will argue that there are 11 that are distinct forms of Remarks, Requests, or Nonverbal Displays. The three general forms, as well as the 11 categories, evolved from a content analysis of four types of material: the categories specified in the 17 surveys, harassment recipients' accounts of their experiences included in other scholarly works (e.g., MacKinnon, 1979; Martin, 1980), court decisions, or interpretations of such decisions (e.g., Vhay) that presented a legal conception of harassment, and the categories specified by the EEOC (1988). These "data" were subjected to content analysis procedures used for developing and refining substantive categories (Krippendorff, 1980; Rosengren, 1981). Refinement of each category's content as well as specifications for determining its uniqueness from others were modified as a result of validity checks. These checks continued until a given harassment incident could be categorized in one and only one category.

Finally, each category was arranged under one of the three general forms (Requests, Remarks, Nonverbal Displays) on the basis of severity. These severity rating determinations were made by adapting the results of the analyses of Fitzgerald and Hesson-McInnis (1989; Table I) and Baker et al. (1990) to our categorization of harassment types. Essentially, the gravity of a harassment experience increases as the content of the initiator's 
behavior becomes more personally and sexually focused on the recipient. The 11 harassment categories are presented in Table III and discussed below.

\section{Verbal Requests}

A "request" differs from a "remark" in that the former is a goal-oriented statement seeking sexual or relational intimacy. While some requests are quite explicit (e.g., quid pro quo), others are much more nebulous and may seem like "remarks" when in fact they are subtle overtures that explore the possibility of a social or sexual encounter. In this regard, there are two types of questions that harassers often ask: those that seek highly personal or sexual information (e.g., body measurements, sexual experiences), and those that seek social or sexual engagement. A researcher can generally determine from the context of the situation in which the question was asked, as well as from the history of the relationships between the harasser and the recipient, whether the questions sought engagement or were vehicles for embarrassing or humiliating a woman. For our purposes, we concur with other research studies by defining the latter as "remarks" rather than "requests."

Sexual Bribery. This involves an explicit quid pro quo of some sort. Loy and Stewart (1984) use the term "verbal negotiations" and Gutek (1985) "expected sexual (or social) activity" to refer to this phenomenon. Usually the threat of punishment or the promise of reward is found in organizational situations where there are clear power differences between harassers and recipients. However, co-workers who have higher job-related status as a result of seniority or experience may also attempt to extort sexual gratification by withholding vital information or training that is necessary for successful job performance (e.g., Walshok, 1981; Martin, 1980).

Several examples in the research literature clearly represent Silverman's (1976) women-as-prostitutes model of harassment: several women indicated that male co-workers offered them money in exchange for sexual favors (e.g., Gruber \& Bjorn, 1982; Walshok, 1981, p. 230). According to one autoworker, a male co-worker "showed me a $\$ 100$ bill and said that he was keeping it warm for me and that it was mine anytime I wanted it." Though sexual bribery is one of the earliest and clearest examples in the law of what constitutes sexual harassment (Vhay, 1988), the majority of research studies do not include this as a separate category of harassment. Apparently such incidents are subsumed under "pressure for sex favors" or "sexual advances." 
Sexual Advances. Unlike bribery, advances do not involve a quid pro quo; and unlike sexual remarks, they do solicit a sexual relationship. The pressures or "overt demands" (Loy and Stewart) are generally in the form of repeated requests, the use of either intimidating or intimate sexual language, or the use of romantic symbols as a means of soliciting sexual consent. As we will discuss later, requests for sex have a lower threshold of tolerability than relational advances and subsequently a smaller number of requests (oftentimes a single request) for sex constitutes harassment (Collins \& Blodgett, 1981; Schneider, 1982).

Sexual advances are harassing not only by virtue of their repetition, but more generally because they distort the balance of a social relationship by seeking a level of intimacy that far exceeds the scope of the relationship. The "pressure" stems from this imbalance-actually an invasion of sexual privacy-in which a more powerful person (usually a male) attempts to redefine a relationship in a self-interested manner (LeMoncheck, 1985). While some requests are fashioned in a crude, direct manner (e.g., "I'd like to fuck your brains out"), others are clothed in "romantic" ("Will you be my lover?") or humorous (e.g., adult greeting cards) terms. All of them may be considered as an invasion of sexual privacy and a distortion of relational balance.

In the research literature, "letters and calls" is presented as a distinct category in three studies. In my view letters (cards) or calls should be properly categorized according to their content-as either remarks or requests. Rather than representing a distinct type of harassment, letters or calls may be viewed as affecting the severity of harassment. Requests made during face-to-face interaction usually have more impact than letters or calls: a woman can tear up a letter without reading it or hang up on a phone call. Such interactive control is oftentimes difficult in work environments where a woman has routine, daily job-related encounters with a harasser. The flip side of greater control is increased vulnerability when harassment at work flows over into letters or calls received at home. Some recipients have had to use unpublished telephone numbers or answering machines to fend off harassment on the home front.

Relational Advances. Most advances or requests are relational rather than sexual in nature (Gruber, 1990). The goal of such "invitations" (Benson \& Thomson, 1982), whether through face-to-face contact or by letters or phone calls, is a social encounter. Relational requests are not apt to be regarded as harassment unless they are repeated (Collins \& Blodgett, 1981; EEOC, 1988; Schneider, 1982). Women frequently complain of being "badgered" for a date or of having to deal with a man who "won't take no for an answer." 
The offensive nature of relational requests is often obscured because of the mixed messages that develop when expressions of sexual interest by a man are displayed in a manner that objectifies a woman (LeMoncheck, 1985). Cultural norms legitimize such advances as a normal means for men to demonstrate their sexual attraction to women. These advances, though less sexual, are generally more harassing in the literal sense, than sexual advances because of their overtness and frequency.

Subtle Advances/Pressures. This category, which appears in 5 studies, is often difficult to use because it requires one to distinguish direct from subtle remarks or requests. A unique characteristic of this category is that the requests are implied, veiled in humor, or carefully constructed grammatically (e.g., double entendres or innuendos). These advances are often in the form of questions seeking information about sexual availability or behavior: "Did you ever have sex outside your marriage?" "Do you believe in oral sex?" "Do you date older (or married) men?" Other advances are statements that denote a man's sexual needs without specific references and make unwarranted assumptions about a woman's availability for meeting such needs, such as "Do you know how big a black man's penis is?" (cited in Mackinnon, 1979, p. 30). "Emotional come-ons" (Benson \& Thomson, 1982) are relevant here because they are a subtle means of developing or intensifying a relationship through self-disclosure. Seen in this way, emotional come-ons are not properly "remarks" usually but are instead subtle "requests" that exert pressure upon a woman by manipulating norms of reciprocity (Schlenker, 1980).

How can subtle advances be distinguished from the not-so-subtle? Is there a distinction between subtle requests and vague remarks? In subthe advances either the goal (e.g., a date, a sexual relationship) or the target (the woman herself) is left unstated. A woman may feel pressure even though the harasser has not specifically stated his intentions, or the needs may be stated explicitly without specific references to the woman. Focusing on the goal is also a useful means for the researcher to distinguish questions that attempt to humiliate or denigrate from those that carefully test the waters for a possible relationship. The discovery of the harasser's intentions is usually retrospective in subtle advances: the meaning of a question or comment becomes clearer to the victim (and secondarily, to the researcher) when it is placed in a context that includes prior and subsequent interactions. For example, a secretary who had worked for her boss for several years was suddenly the recipient of cards (signed innocuously "Your boss") and small gifts over a period of several months. These gifts made her feel both deeply uneasy, because they were inappropriate, as well as guilty, for being suspicious of his motives, until the day he confessed that his marriage was over and that he was "madly in love" with 
her and wanted her as his lover (McMahan v. West Huron Management, Co., 1984). The uneasiness she experienced when she received the gifts and attention "made sense" when given a retrospective interpretation (Hewitt, 1984, p. 243).

\section{Sexual Remarks/Comments}

Most of the statements in this category are either personally demeaning statements or questions or else general sexual remarks about women. Unlike requests, remarks do not have relationship-oriented goals. Instead, the goals of remarks vary from expressions of sexual interest to attempts to publicly humiliate a woman.

Personal Remarks. This category includes sexual jokes, teasing, or questions of a personal nature that are offensive or embarrassing and are made to a woman. Most of what researchers refer to as "sexual comments" or "teasing/questions/remarks" fit under this heading.

Also included in this category are statements or questions about a woman's sexuality or physical appearance, or comments demeaning a woman through the use of vulgar, sexist terminology. What distinguishes this category from the next one is the fact that a male co-worker is talking to a woman rather than about her. While some comments are disguished as jokes or frivolous statements (e.g., supervisor to woman autoworker: "I lose my concentration each time you bend over"; police sergeant to female officer: "Is that a pea in your pocket or are you just happy to see me?"), still other comments do not attempt to be humorous or "complimentary" but rather reveal anger and domination. In a recent case, one of the plaintiffs, a 50+-year old typesetter was sprayed with dog deodorant on several occasions by a male co-worker and told "Your cunt stinks" (Cote et al. $v$. Detroit Free Press, 1984).

From my research and consulting work and that of others, it seems that there is a lack of consensus among laypersons as to the types of questions or statements that constitute sexual harassment. Research on perceptions of sexual harassment (Gutek, 1985; Terpstra \& Baker, 1987; USMSPB, 1981) reveals that people, in particular men, are not apt to label a statement or question as being sexually harassing if it involves humor or an attempt to be complimentary. The fact that comments range from the teasing-complimentary variety to the overtly outrageous and demeaning suggests that degree of aversiveness needs to be addressed as a factor in assessing harassment severity.

Finally, some questions of a highly personal or suggestive nature are properly viewed as remarks rather than requests even though there is an 
explicit solicitation. The researcher should note, as the target herself does, that the primary goal of the statement was verbal mortification (Goffman, 1961) rather than sexual contact. Martin (1980) provides an excellent example:

She (a police trainee) and several other students at the academy were assigned to a special detail to protect a visiting dignitary's hotel. A sergeant, in front of the other recruits, said to her 'Come on, I have a room. I want a header'. She was shocked and dismayed, less at the suggestion of the sexual act than the fact that it was made in front of others and calculated to humiliate her. (p. 145, emphasis added)

Subjective Objectification. This term, borrowed from Benokraitis and Feagin (1986), is used to refer to situations where a target woman is a topic of sexual conversations among her male co-workers. There are two prime examples of such objectification from the research: one is where a woman is forced to listen to men in her immediate work area talk to each other about her in a highly sexualized manner; the second includes instances where a woman discovers that she has been the object of rumors or gossip among male co-workers who have denigrated her sexuality, appearance, and the like. An example of the latter is given by an autoworker (Gruber \& Bjorn, 1982) who told of how after she had gone to McDonald's for lunch with a male co-worker, he told the men in his work group that they had gone to a motel for a "quickie." Martin (1980) provides an example of the other type of objectification: "One female officer reported that when signing out, several officers looked at her chest and remarked 'How long do you think she can float?' as others stood chuckling" (p. 145).

Objectified comments often spark different types of anger and frustration from women than direct statements do. Direct comments are more assaultive generally by virtue of the face-to-face nature of such encounters. These encounters often create simultaneous feelings of rage and fear. In contrast, indirect comments objectify a woman in a double sense: she is treated as a nonperson, who, similar to a child, mental patient, or servant (Goffman, 1961, 1977), is not formally acknowledged as a co-participant in social interactions; and her sexuality, as opposed to personal or professional characteristics, is the topic of discourse. Being treated as an "invisible" sex object seems to spark a diffuse anger accompanied by acute frustration because the sources of the harassment are often either too numerous (as when an entire work group participates) or too unidentifiable (as when a rumor has passed through an unknown number of workmates). Unfortunately for social researchers, existing categories of sexual harassment do not distinguish these types of remarks from others.

Sexual Categorical Remarks. Comments under this category reflect what is referred to as a "hostile or intimidating environment" in legal terms 
(e.g., see EEOC, 1988). Statements of this sort indirectly malign a woman by denigrating the social category of which she is a member or by sexually objectifying other women (e.g., co-workers or women familiar to the victim). Such remarks, as well as Sexual Materials, are elements of identity stripping or mortification (Goffman, 1961). The objects of some remarks are generic or unspecified, such as references to women as "titties" (Moser and Cooper v. Churchill Transportation, 1984). One of Schneider's (1987) respondents describes the chilling effect that an instructor's rape jokes had on her academic performance. Other comments are directed at individual women familiar to the victim, or toward groups of women (e..g, those who work in a specific job category). As an example of the latter, women printers in the composition room of a large urban newspaper were labeled the "cunt brigade" by their male counterparts. (Cote et al. v. Detroit Free Press, 1984).

Caution should be exercised in tabulating only those comments that are sexually based and not simple sexist. Though sexist remarks (e.g., "Women don't belong here") certainly may contribute to the creation of a hostile or intimidating environment, only those that are sexually based are technically instances of sexual harassment. Research by Fitzgerald and Hesson-McInnis (1989) gives empirical support for this distinction. They found that sexist comments and gender favoritism were perceived by research subjects as distinct from scenarios containing sexual interactions (e.g., seductive behavior, sexual imposition).

\section{Nonverbal Displays}

The four types of nonverbal displays vary markedly in the degree to which they are personal. Some, like pornographic pictures or cartoons, are less severe than others, such as uninvited touching. The most severe, of course, is sexual assault.

Sexual Assault. Previous studies have found that 1-3\% of women report actual or attempted rape. What differentiates this category from the one below is the aggressive and coercive nature of the act. MacKinnon (1982) rightfully criticizes definitions of sexual assault that focus only upon actual or attempted sexual penetration. It is our view that actions that involve physical force (and hence engender resistance) of a sexual nature should be categorized as "assault" whether or not intercourse is attempted.

Sexual Touching. The literature reveals that most touching consists either of contact with a sexual part of a woman's body, or sexualized contact. The former has been described as "manhandling" (Loy \& Stewart, 1984) and "physical attacks" (Gruber \& Bjorn, 1982). With regard to sexualized 
contact, the harassing nature of the touching has usually been minimized by research procedures that truncate women's descriptions of the harassment episode. The offensive nature of touches on the arm or back, of hugs or "friendly" embraces, may not have the impact on the researcher that they did upon the victim unless she is allowed to describe the context of the harassment and details of specific actions.

Sexual Posturing. This, the second most frequent form of sexual harassment (Gruber, 1990), refers to gestures or behaviors of a sexual nature that do not involve physical contact. The 15 studies that include a "looks/stares/gestures" or "body language" category do not distinguish clearly between offensive acts that are done to a woman and those that are done in her presence as a bystander. The research literature has created some confusion by frequently lumping touching and cornering together (i.e., "touching/cornering" category), thereby confusing contact and noncontact harassment (e.g., see USMSPB, 1981; Stringer-Moore, 1982; McIntyre, 1982).

It is our view that noncontact harassment should be regarded separately, and differences among the types of sexual postures should be based on the degree to which they are oriented personally at the recipient or the extent to which they invade the target's personal space. Women have reported a variety of advances of a close or personal nature including following, cornering, staring, and feigning or attempting physical contact with the target. There has been little research on sexual posturing that involves a woman as a bystander rather than as an explicit target. This is important for researchers to include because the EEOC (1988) views this as a relevant factor in the creation of a "hostile and intimidating" environment.

Two examples illustrate this form of harassment: a woman works in the midst of male co-workers who feign masturbation or anal intercourse while bantering with each other (see Hearn and Parkin, 1987), or a woman watches one or more men sexually harass other women. In a recent case (Lesert v. Montgomery Ward, 1985) several women alleged harassment because they were subjected to the blatant and routine grabbing, fondling, and kissing activities of their supervisor toward young (and usually newly hired) salesclerks. Further research is needed to understand in what ways women "bystanders" are affected by the harassment of others, and how it affects the way they handle acts of harassment that involve them personally. Such research will increase our knowledge of this specific legal aspect of harassment and of what Gutek (1985) calls a "sexualized" environment.

Sexual Materials. There is a parallel between this category and "Sexist Categorical Remarks" insofar as both are often nonpersonal. In contrast to the latter, however, materials or objects have an enduring presence in many work environments. Oftentimes pornographic pictures or posters and 
sexual graffiti are present in workplaces over an extended period of time, especially in male-dominated jobs, and become part of the occupational landscape. The proliferation of sexual materials in a workplace that are of a nonpersonal and subsequently "environmental" nature should be distinguished from material that is personally directed. Court cases provide some excellent samples of the latter: a hand-drawn pornographic cartoon that was taped to the back of a female employee (Eide v. Kelsey-Hayes, 1980), a woman who repeatedly found sexual graffiti bearing her name attached to the staff refrigerator (Porta v. Rollins Environmental Services, cited in Murray, p. 472), and a supervisor who repeatedly showed a female employee nude photographs (Kats v. Dole, cited in Brown, p. 453).

A different form of harassing sexual materials results from the profanation of women's sexuality, personal space, or personal objects. As is true with other forms of sexual material, profanation may be either environmental or personal. A woman whose supervisor kept track of her menstrual cycle on his calendar (Coley v. Consolidated Rail Corp., cited in Brown, p. 453), a police officer who found bear testicles in her desk drawer one morning, the legal secretaries who found feminine napkins with red ink spots rolled into their typewriters (McClean v. Ward et al., 1984), and the women in the composition room of a newspaper who witnessed male co-workers fondling and exchanging the panties of the woman-friend of one of the men (Cote et al v. The Detroit Free Press, 1984) are examples of profanation from court cases.

\section{DISCUSSION}

It has been difficult for researchers to ascertain the extent and types of harassment found in work and educational environments because of what is counted as sexual harassment and, secondarily, how data on the phenomenon are collected. Research has not specified clearly the distinctions between remarks and requests, nor has it delineated the subtypes of each. As a result, contextual variations of remarks-whether a woman is addressed directly, talked about in her presence as if she were invisible, or discussed as a member of a social category-are lost when such distinctions are subsumed under "remarks." Still other important aspects of harassment have been "lost" by being ignored altogether. This is especially the case where research has focused primarily on interpersonal forms of harassment. Environmental forms, which often only involve a woman indirectly, need greater research attention because of the potential "chilling" effect that such harassment may have on work relationships and job-related attitudes. 
Little is known, for example, about women's experiences with, and reactions to, bystander harassment.

As a result of these omissions, researchers have failed to capture both the variety and the complexity of typical harassment episodes. The challenges in this decade for researchers are to expand the definitions and measures to embrace the full spectrum of harassment as well as to use a multimethod approach when collecting data. What has been done well, and what needs to be done in the future, is summarized below.

1. Because the categories developed for the USMSPB survey have been adapted by some other researchers (e.g., Stringer-Moore, Verba et al.), we do have a fairly clear idea of the prevalence of some forms of harassment in quite different environments. For example, date or relational pressures account for approximately 1 of 8 harassment experiences while sexual comments represent more than a quarter (see Gruber, 1990, Table 4). When nonverbal behaviors are reclassified as either contact or noncontact in those research studies that provide sufficient information to allow a reader to make such a distinction, we find that sexual looks and gestures (or sexual posturing) occurs nearly as frequently as sexual comments. Finally, acts involving contact occur less frequently than verbal requests, and the latter occur with greater frequency than verbal comments.

2. Despite the significant insights provided by major large-scale studies, the problem of exhaustiveness has implications for both the scholarly and the legal-policy realms. First, researchers probably underestimate the actual amount of harassment since most studies up to this point have deemphasized environmental and nonpersonal forms of harassment. This means, for example, that when the USMSPB survey finds $42 \%$ of women federal employees have experienced harassment, then the "real" percentage of harassed women is actually larger. Second, since environmental forms of harassment have emerged in recent years as legal and policy issues, researchers cannot provide meaningful data to this new area unless the existing conceptualizations of harassment are expanded. Specifically, this means that we must devote greater attention to Sexual Materials, Sexual Categorical Remarks, and different manifestations of bystander harassment.

3. Finally, social researchers need to expand the manner in which harassment is studied so as to include diverse methodologies. Most major research studies have used survey research techniques. While such approaches have yielded excellent "snapshots" of the forms and the correlates of harassment, they have provided little understanding of the contextual aspects.

Excerpts from research interviews and court cases have been used in this paper because they provide a greater context for harassment experiences: we derive a better sense of how a woman's response was shaped by 
her previous interactions with the harasser, by the presence of other males during the interactions, or her awareness of the experiences that fellow workers have had with harassment. Indeed, researchers who rely on survey research may underestimate the general effect on morale that sexual harassment has on many workplace or educational environments apart from the effects it has on individual recipients of personal harassment. While surveys have been fruitful for tapping the more overt or personally directed forms of harassment, their weaknesses lie in not understanding harassment that has a "history" (i.e., develops over a time period), which is subtle or indirect, or which envelopes a significant part of a work environment. Such information is more apt to be collected through the use of either intensive interviews or unobtrusive methods that might use the categories developed in this paper as guides. These categories could be used also in surveys to derive a more general understanding of harassment frequencies and correlates.

\section{REFERENCES}

Baker, D., Terpstra, D., and Larntz, K. (1990). The influence of individual characteristics and severity of harassing behavior on reactions to sexual harassment. Sex Roles, 22, 304-325.

Benokraitis, N. \& Feagin, J. (1986). Modern sexism. Englewood Cliffs, NJ: Prentice-Hall.

Benson, D., \& Thomson, G. (1982). Sexual harassment on a universily campus: the confluence of authority relations, sexual interest, and gender stratification. Social Problems, 29, 236-251.

Brown, N. (1988). "Meritor Savings Bank vs. Vinson: clarilying the standards of hostile working environment sexual harassment." Houston Law Review, 25, 441-470.

Cammaert, L. (1985). How widespread is sexual harassment on campus? International Joumal of Women's Studies, 8, 388-397.

Canadian Human Rights Commission. Unwanted sexual altention and sexual harassment. Montreal: Minister of Supply and Services of Canada.

Collins, E., \& Blodgett, T. (1981). Sexual harassment: Some see it, some won't. Harvard Business Review, 59, 77-95.

Cote et al. v. Detroit Free Press. (1984). United States District Court, Eastern District of Michigan, No. 84-CU-4837-AA.

Eide and Eide v. Kelsey-Hayes. (1980). State of Michigan in the Circuit Court of Wayne County, No. 80-045144-C2.

Equal Employment Opportunity Commission. Guidelines on discrimination because of sex. 29CFR Part 1604, Federal Register, November 10, 1980, 45.

Equal Employment Opportunity Commission. EEOC Policy Guidance. N-915.035.5168, October 25, 1988, pp. 6472-6489.

Fitzgerald, L., \& Hesson-McInnis, M. (1989). The dimensions of sexual harassment: A structural analysis. Journal of Vocational Behavior, 35, 309-326.

Gillespie, D., \& Leffler, A. (1987). The politics of research methodology in claims-making activities. Social science and sexual harassment. Social Problems, 34, 490-508.

Goffman, E. Encounters. Indianapolis, IN: Bobbs-Merrill.

Goffman, E. (1977). The arrangement between the sexes. Theory of Society, 4, 301-331.

Gruber, J. E. (1990). Methodological problems and policy implications in sexual harassment research. Population Research and Policy Review, 9, 235-254. 
Gruber, J., \& Bjorn, L. (1982). Blue collar blues: The sexual harassment of women autoworkers. Work and Occupations, 9, 271-298.

Gutek, B. (1985). Sex and the workplace. Jossey-Bass: San Francisco.

Hayler, B. (1979). Report of Illinois Task Force on Sexual Harassment. Testimony before the State of Illinois Judiciary Committee, March, 4.

Hearn, J., \& Parkin, W. (1987). Sex at work: The power and paradox of organization sexuality. New York: St. Martin Press.

Hewitt, J. (1984). Self and society: A symbolic interactionist social psychology. Boston: Allyn and Bacon.

Krippendorf, K. (1980). Content analysis: An introduction to its methodology. Beverly Hills, CA: Sage Publications.

Lafontaine, E., \& Tredeau, L. (1986). The frequency, sources, and correlates of sexual harassment among women in traditional male occupations. Sex Roles, 15, 433-441.

LeMoncheck, L. (1985). Dehumanizing women: Treating persons as sex objects. New York: Rowman and Allenheld.

Lesert v. Montgomery Ward and R. Parker. (1985). State of Michigan in the Circuit Court of Kent County, No. 85-49283-N2.

Littler-Bishop, S., Seidler-Feller, D., \& Opaluch, R. (1982). Sexual harrasment in the workplace as a function of initiator's status: The case of airline personnel. Joumal of Social Issues, 38, 137-148.

Loy, P., \& Stewart, L. (1984). The extent and effects of the sexual harassment of working women. Sociological Focus, 17, 31-43.

McIntyre, D. (1982). Sexual harassment in government: The situation in Florida and the nation. Dissertation, Tallahassee: Florida State University.

MacKinnon, C., (1979). Sexual harassment of working women: $A$ case of sex discrimination. New Haven, CT: Yale University Press.

MacKinnon, C. (1982). Feminism, Manism, method and the state: An agenda for theory. Signs, 7, 515-544.

Mackinnon, C. (1989). Sexuality, pornography, and method: 'Pleasure under patriarchy.' Ethics, 99, 314-346.

McKinney, K. (1990). Sexual harassment of university faculty by colleagues and students. Sex Roles, 23, 421-438.

McMahan, v. West Huron Management Co. (1984). State of Michigan in the Circuit Court of Oakland County, No. 84-286-111-NO.

Martin, S. (1980). Breaking and entering: Policewomen on patrol. Berkeley: University of California Press.

Maypole, D. (1986). Sexual harassment of social workers at work. Social Work, 31, 29-34.

Maypole, D., \& Skaine, R. (1982). Sexual harassment of blue collar workers. Journal of Sociology and Social Welfare, 9, 682-695.

Murray, P. J. (1988). Employer: beware of 'hostile environment' sexual harassment. Duquesne Law Review, 26, 461-484.

Rosengren, K. (1981). Advances in content analysis. Beverly Hills, CA: Sage Publications.

Schlenker, B. (1980). Impression management. Monterey, CA: Brooks/Cole.

Schneider, B. (1982). Consciousness about sexual harassment among heterosexual and lesbian women workers. Social Issues, 38, 75-98.

Schneider, B. (1987). Graduate women, sexual harassment and university policy. Journal of Higher Education, 58, 46-65.

Silverman, D. (1976). Sexual harassment: Working women's dilemma. Quest: A Feminist Quarterly, 3, 15-24.

Stringer-Moore, D. (1982). Sextal harassment in the Seattle city workforce. Seattle: Office for Women's Rights.

Terpstra, D., \& Baker, D. (1987). A hierarchy of sexual harassment. Journal of Psychology, 12, 599-605.

United States Merit Systems Protection Board. (1981). Sexual harassment in the federal workplace. Washington, DC: Government Printing Office. 
Verba, S., DiNunzio, J., \& Spaulding, C. (1983). Unwanted attention: Report on a sexual harassment survey. Report to the Faculty Council, Harvard University.

Vhay, M. (1982). The harm of asking: Toward a comprehensive treatment of sexual harassment. University of Chicago Law Review, 55, 328-362.

Walshok, M. (1981). Blue-collar women: Pioneers on the male frontier. Garden City, NJ: Anchor Books.

Webking, E. (1979). A study of sexual harassment in Lethbridge. Lethbridge: Citizens' Human Rights Council. 